Volume 7 Nomor 1, April 2021

\title{
PENGARUH PRAKTIK SUMBER DAYA MANUSIA TERHADAP PERILAKU KEWARGANEGARAAN ORGANISASI
}

\author{
Basuki \\ Email: msibasukidr@gmail.com \\ Rahmi Widyanti \\ Farida Yulianti \\ Lamsah \\ Universitas Islam Kalimantan MAB Banjarmasin
}

\begin{abstract}
The relationship between human resource management and organizational performance is very important to understand. Good human resource practices within the company can increase the good behavior of members of the organization.

This study aims to determine how practices in human resources affect organizational citizenship behavior (OCB). OCB represents the additional contribution of the employee to the company and, however, the actions that the employee expects in a crisis scenario or a change in timing by the manager. In this study, it uses five main indicators in human resource management practices in organizations according to the HR field: recruitment and selection, training and development, remuneration, performance appraisal, and working conditions. Organizational Citizenship Behavior Scale (SPKO), which contains five dimensions: disclosure of organizational image; creative suggestions; protection of organizational assets; professional preparation and cooperation with colleagues. Data were collected from 56 employees of wood processing companies located in Banjarmasin City. Data analysis used Partial Least Square (PLS) with SmartPLS software.

The results show a significant effect of human resource practices on OCB, and this study proves that only professional involvement shows a significant relationship. This study concludes that human resource practices influence the dissemination of organizational images and creative suggestions from the OCB factor.
\end{abstract}

Keywords: Human Resource Management Practice, Organizational Citizenship Behavior.

\section{PENDAHULUAN}

Ketika dipekerjakan oleh sebuah organisasi, pekerja membawa serta pengalaman yang diperoleh di organisasi tempat mereka sebelumnya bekerja selama karir profesional mereka, serta pengetahuan yang diperoleh di lembaga pendidikan yang mereka hadiri dan keterampilan yang dikembangkan sepanjang karir mereka. Namun, meskipun kami tidak bermaksud untuk membahas pentingnya pengalaman dan pengetahuan atau keterampilan, ada pendekatan yang muncul yang diterjemahkan menjadi kebutuhan untuk mempelajari 
dan menerapkan kapasitas psikologis sumber daya manusia yang dapat diukur, dikembangkan dan dikelola untuk meningkatkan kinerja organisasi (Luthans, 2002).

Menurut Legge (2006) dan Armstrong (2009) menegaskan bahwa bidang sumber daya manusia telah mengambil peran strategis dan relevan dalam proses peningkatan kesadaran, membuat dan memperbarui kebijakan dan praktik mereka, mengarahkan mereka lebih dan lebih lagi untuk kepentingan karyawan mereka, mengingat mereka adalah aktor utama dalam pencapaian hasil, karena mereka adalah penghasil pengetahuan, inovasi dan kapasitas organisasi.

Istilah "praktik", pada gilirannya, digunakan dalam arti kebiasaan, rutinitas atau tindakan, atau saat merujuk pada aktivitas yang merupakan komponen rutinitas (Dessler, 2010). Di sisi lain, perilaku individu dalam proses ini bersifat fundamental, karena secara langsung mempengaruhi baik produktivitas individu maupun produktivitas kelompok kerja mereka dan, akibatnya, organisasi.

Sadar akan pentingnya jenis perilaku ini untuk menghadapi daya saing global dan kebutuhan akan inovasi yang berkelanjutan, organisasi semakin menuntut warga organisasi (Dubrin, 2003). Oleh karena itu, tujuan dari penelitian ini adalah untuk menganalisis bagaimana praktik di bidang sumber daya manusia (PSDM) mempengaruhi perilaku kewarganegaraan organisasi (PKO). Oleh karena itu, artikel ini menyajikan penelitian dengan 156 pekerja, yang menunjukkan dampak PSDM pada PKO, melalui studi kuantitatif yang instrumen pengumpulan datanya diatur dalam kuesioner yang diisi sendiri.

\section{TINJAUAN TEORITIS}

\section{PRAKTIK SUMBER DAYA MANUSIA}

Dessler (2010) mendefinisikan manajemen SDM (HRM) sebagai satu set terintegrasi dari strategi, kebijakan dan praktik yang direncanakan dan dimaksudkan untuk mengelola orang dalam suatu organisasi; dan praktik HRM sebagai aktivitas yang benar-benar dilaksanakan dan dialami oleh karyawan, dan dapat diverifikasi secara obyektif. Penulis menekankan integrasi yang harus ada antara praktik manajemen SDM dan kemungkinan internal dan eksternal organisasi. 
Lepak $d k k$. (2006) mempertanyakan penelitian tentang subjek dalam kaitannya dengan keragaman nomenklatur internasional dan mencoba memperjelas istilah tersebut.

Praktik SDM berada pada tingkat analisis terendah dan mengacu pada tindakan terisolasi yang dipilih organisasi untuk mencapai beberapa hasil tertentu, seperti wawancara perilaku, sosialisasi karyawan, evaluasi $360^{\circ}$, dan lain-lain. Kebijakan SDM berada pada tingkat analisis kedua dan mewakili karyawan program yang berfokus pada, yang harus memengaruhi pilihan Praktik SDM, misalnya, kebijakan pembayaran kinerja harus mencerminkan pilihan praktik seperti bagi hasil dan pendapatan variabel.

Meskipun sistem SDM dapat menyamai hasil organisasi dan mencerminkan keunggulan kompetitif yang lebih besar, Lepak $d k k$ (2006) mempertanyakan kesulitan menjalankan konstruksi ini dalam penelitian, dalam hal kisaran definisi yang muncul dalam literatur dan kesulitan mengevaluasi integrasi antara ini dan kebijakan dan praktik masingmasing.

Penelitian internasional telah menghubungkan PSDM dengan proyek-proyek yang berhasil (Khan; Rasheed, 2015); ketidakhadiran, niat untuk tetap dalam organisasi, perilaku kewarganegaraan organisasi dan komitmen afektif (Kehoe; Wright, 2013); keterlibatan, perilaku kewarganegaraan organisasi dan niat untuk meninggalkan organisasi.

Penelitian ini bertujuan untuk menganalisis hubungan masing-masing dimensi - atau subsistem - pada perilaku kewarganegaraan organisasi, berusaha mengidentifikasi kebijakan mana yang memiliki dampak yang lebih besar atau lebih kecil terhadap perilaku pekerja. Jadi, enam dimensi yang dianalisis adalah: rekrutmen dan seleksi; keterlibatan; pelatihan dan pengembangan; kondisi kerja; penilaian kinerja dan kompetensi; dan remunerasi dan insentif.

Menurut Dessler (2010), kebijakan dan praktik rekrutmen dan seleksi didefinisikan sebagai proposal organisasi untuk mencari karyawan, merangsang mereka untuk menerapkan dan memilih mereka, berusaha menyelaraskan kompetensi orang tersebut dengan karakteristik dan tuntutan organisasi. Kebijakan keterlibatan adalah proposal organisasi yang diartikulasikan untuk menciptakan ikatan afektif dengan kolaboratornya, berkontribusi pada kesejahteraan mereka, dalam hal pengakuan, hubungan, partisipasi dan komunikasi. Pelatihan dan pengembangan mencakup ketentuan kepada karyawan tentang 
perolehan keterampilan yang sistematis dan dorongan untuk pembelajaran dan produksi pengetahuan yang berkelanjutan. Dimensi kebijakan yang berfokus pada keselamatan dan manfaat, dan menamakannya sebagai kebijakan kondisi kerja. Definisi penulis dari kebijakan ini adalah proposal organisasi yang diartikulasikan untuk menyediakan kondisi kerja yang baik kepada karyawan dalam hal manfaat, kesehatan, keselamatan, dan teknologi.

\section{PERILAKU KEWARGANEGARAAN ORGANISASI (PKO)}

Organisasi adalah sistem kegiatan atau kekuatan pribadi yang terkoordinasi secara sadar. Dengan demikian, kerja kolektif diterjemahkan ke dalam kebutuhan akan tujuan bersama, semangat kerja sama dan, di atas segalanya, pembentukan norma dan peraturan. Demikian pula, keberadaan suatu kegiatan yang terorganisir hanya dimungkinkan jika ada niat baik, spontanitas atau kecenderungan pribadi untuk bekerjasama (Widyanti, Rahmi, 2019).

Untuk perilaku spontan individu, Katz dan Kahn (1978) untuk pertama kalinya menggunakan istilah warga organisasi. Bagi mereka, individu memiliki hak dan kewajiban serta mampu menyumbang ke organisasi. Para penulis ini menemukan dalam konsep kewarganegaraan istilah yang tepat untuk merujuk pada perilaku sukarela individu dalam organisasi.

Konsep memberi demi organisasi, yang dikemukakan oleh Katz dan Kahn (1978) secara bertahap digantikan oleh konsep lain: pertukaran, yang dihasilkan oleh prinsip timbal balik, sedangkan Widyanti, R., (2021) mendefinisikan kewarganegaraan organisasional sebagai manifestasi dari perilaku sukarela yang baik, yang melampaui kewajiban formal dan kemungkinan jaminan dari imbalan kontrak.

Masalah kinerja di tempat kerja memiliki dua bagian - PKO dan tugas; dan bahwa mereka berbeda dalam tingkat kepentingan dan jaminan penghargaan, tetapi PKO tidak dapat dianggap di luar konteks organisasi atau tanpa penghargaan.

Dimensi Kerjasama dengan Kolega (KK) mencakup tindakan menawarkan bantuan dan dukungan kepada rekan kerja dalam organisasi (Bastos et al., 2014). Ini merupakan isyarat 
sukarela untuk membantu seorang kolega ketika mereka memiliki masalah yang berhubungan dengan pekerjaan; Demonstrasi kemampuan pekerja untuk menangani konflik interpersonal, memfasilitasi hubungan antara individu, dalam rangka memelihara lingkungan kerja yang harmonis; dorongan; memperkuat pemenuhan profesional dan pengembangan rekan kerja dan tampilan gerakan pencegahan dan perencanaan, untuk menghindari masalah. Perilaku seperti itu dijelaskan oleh Podsakoff et al. (2000) dan Organ, Podsakoff dan Mackenzie (2006).

\section{HUBUNGAN ANTARA KEBIJAKAN DAN PRAKTIK DALAM SUMBER DAYA MANUSIA DAN PERILAKU WARGANEGARA ORGANISASI}

Lam, Chen dan Takeuchi (2009) Mempelajari bagaimana PSDM mempengaruhi PKO dalam perusahaan patungan Jepang, yang berlokasi di Cina. Penelitian ini menguraikan tiga tujuan: untuk mengeksplorasi bagaimana PSDM mempengaruhi PKO, bagaimana dampak PKO pada niat keluar masuk karyawan dan apakah PKO berfungsi sebagai variabel mediasi antara PSDM dan niat keluar. PSDM yang dipelajari adalah rekrutmen dan seleksi, remunerasi, pelatihan dan pengembangan, serta evaluasi kinerja. Hasil penelitian kuantitatif menunjukkan bahwa kebijakan SDM secara signifikan berdampak pada perilaku kewarganegaraan organisasi individu, dan bahwa kebijakan pelatihan dan pengembangan serta keterlibatanlah yang menyebabkan dampak terbesar.

Temuan dari Snape dan Redman (2010) yang meneliti pengaruh PSDM pada PKO di kalangan pekerja Inggris. Salah satu tujuan dari penelitian ini adalah untuk menganalisis apakah dukungan organisasi memediasi hubungan antara PSDM dan PKO. Hasil kuantitatif menunjukkan bahwa ketika pekerja memandang bahwa dukungan organisasi melebihi pekerjaan yang mereka lakukan, PSDM yang dibentuk oleh organisasi berpengaruh positif terhadap PKO. Namun, jika dukungannya sederhana dan terbatas pada kewajiban perusahaan untuk menjalankan tugas, bahkan dengan mempertahankan PSDM yang sama, perilaku kewarganegaraan organisasi akan terpengaruh secara merugikan.

Estivalete $d k k$. (2013) meneliti produksi ilmiah internasional antara 2002 dan 2012 tentang PKO dan menyimpulkan bahwa, dari 118 studi empiris yang membahas PKO sebagai variabel independen, 22 di antaranya berhubungan dengan hubungan antara PKO dan 
keadilan organisasi, 17 dengan hubungan PKO dan kepemimpinan, 12 antara PKO dan kinerja di tempat kerja, 12 antara PKO dan kepuasan kerja, dan 10 antara PKO dan komitmen organisasi.

Dengan demikian, model teoritis diasumsikan berdasarkan hubungan antara kebijakan dan praktik sumber daya manusia dan perilaku kewarganegaraan organisasi, menurut bidang konseptual yang disajikan pada bagian sebelumnya.

\section{METODOLOGI}

Penelitian ini dirancang menggunakan pendekatan kuantitatif. Instrumen pengumpulan data berupa kuesioner yang diisi sendiri yang terdiri dari Skala Praktik Sumber Daya Manusia, disusun dan divalidasi oleh Demo (2012), terdiri dari 40 item, didistribusikan dalam enam faktor, yang mengukur persepsi karyawan terhadap praktik di Manajemen sumber daya manusia (SDM) dan Skala Perilaku Kewarganegaraan Organisasi, ditingkatkan oleh Bastos, Siqueira dan Gomes (2014), terdiri dari 14 item, didistribusikan dalam tiga faktor, yang mengukur perilaku kewarganegaraan organisasi pekerja.

Dalam penelitian ini, dikumpulkan data dari karyawan perusahaan plywood 56 pekerja berpartisipasi dalam penelitian ini, mengisi kuesioner, sehingga peserta mendapatkan kuisioner versi cetak dan sebelum diisi mereka diberikan kuisioner. dipandu tentang tujuan penelitian.

Pengujian pengaruh dianalisis dengan Structural Equation Model yang diestimasi dengan metode PLS pada software SmartPLS 2.0. Telah dilakukan analisis statistik melalui Koefisien Jalur dan $\mathrm{R}^{2}$, Tes Bootstrap dan uji $t$.

\section{HASIL PENELITIAN}

Hasil demografi responden menunjukkan bahwa sebagian besar responden berjenis kelamin laki-laki 61, $39 \%$ dan perempuan 38,61\%. Rentang usia responden antara 19-46 tahun dengan status perkawinan sebagian besar sudah menikah $73 \%$. Tingkat pendidikan responden sebagian besar SLTA sebanyak 51,3\% dan pernah mengikuti pendidikan di perguruan tinggi sebanyak $23 \%$. Sebagian besar responden sudah lama bekerja di perusahaan antara 10-15 tahun sebanyak $64 \%$.

Tabel 1 dari jumlah item, kisaran tanggapan, sarana, standar deviasi, koefisien variasi dan alpha Cronbach dari faktor-faktor yang membentuk skala PSDM. Sebagian besar 
koefisien variasi menyajikan nilai di atas $30 \%$ dan semua nilai yang ditemukan untuk Cronbach's Alpha lebih tinggi dari 0,70, sehingga menunjukkan, keandalan dan variabilitas yang tinggi diperlukan untuk jenis penelitian ini.

Tabel 1 Analisis Deskriptif dari dimensi PSDM dan PKO

\begin{tabular}{|l|c|c|c|c|c|c|}
\hline Dimensi & Items & $\begin{array}{c}\text { Skala } \\
\text { Jawaban }\end{array}$ & Rerata & $\begin{array}{c}\text { Standar } \\
\text { Deviasi }\end{array}$ & $\begin{array}{c}\text { Koefisien dari } \\
\text { variasi }\end{array}$ & $\begin{array}{c}\text { Cronbach's } \\
\text { Alpha }\end{array}$ \\
\hline IMAG_DISC & 5 & $1-5$ & 3.13 & 1.09 & $35.0 \%$ & 0.91 \\
\hline COOP_COL & 4 & $1-5$ & 4.17 & 0.74 & $18.0 \%$ & 0.78 \\
\hline INVOLV & 12 & $1-5$ & 2.97 & 0.96 & $32.5 \%$ & 0.91 \\
\hline TRAIN\&DEV & 6 & $1-5$ & 2.84 & 1.09 & $38.4 \%$ & 0.87 \\
\hline WORK_COND & 6 & $1-5$ & 3.12 & 0.97 & $31.2 \%$ & 0.74 \\
\hline PE.EVA\&Comp & 5 & $1-5$ & 2.52 & 1.18 & $47.0 \%$ & 0.91 \\
\hline REM\&REW & 5 & $1-5$ & 2.64 & 1.04 & $39.4 \%$ & 0.82 \\
\hline CREAT_SUG & 5 & $1-5$ & 3.05 & 1.01 & $33.0 \%$ & 0.90 \\
\hline
\end{tabular}

Sumber: data primer, diolah, 2020

Pada Tabel 1, dapat dilihat bahwa OID dan dimensi CS menyajikan variasi koefisien rata-rata, Namun dimensi CC menyajikan koefisien variasi yang rendah (kurang dari 0,20), mengungkapkan bahwa persepsi responden mengenai dimensi ini serupa. Semua nilai yang ditemukan untuk Cronbach's alpha lebih tinggi dari 0,70 yang menunjukkan, oleh karena itu, keandalannya tinggi.

Untuk melakukan perhitungan yang diperlukan untuk validasi model struktural penelitian ini, digunakan perangkat lunak SmartPLS versi 2.0 (Ringle; Wende; Becker, 2014) dan untuk menguji validitas konvergen dan diskriminan dari konstruksi yang digunakan dalam model struktural, kami melakukan Analisis Faktorial (Hair JR. et al., 2010).

Hasil analisis faktor, semua konstruk menyajikan indikator dengan beban tinggi pada variabel latennya dan beban rendah pada variabel laten lainnya, menunjukkan diskriminan yang wajar dan validitas konvergen (Chin, 2000; Hair, 2010). Satu-satunya indikator yang tidak menyajikan nilai lebih tinggi dari 0,70 adalah N16, N29 dan N30, yang dikeluarkan dari analisis. 
Volume 7 Nomor 1, April 2021

Tabel 2 Average Extracted Variance, Reliability and Commonality

\begin{tabular}{lccc}
\hline Constructs & $\begin{array}{c}\text { Average Variance } \\
\text { Extracted from } \\
\text { constructs }\end{array}$ & $\begin{array}{l}\text { Composite } \\
\text { Reliability }\end{array}$ & Commonality \\
\hline $\begin{array}{l}\text { Performance Evaluation } \\
\text { \&Comp }\end{array}$ & 0.73 & 0.93 & 0.73 \\
\hline Work Conditions & 0.54 & 0.83 & 0.54 \\
\hline $\begin{array}{l}\text { Cooperation with } \\
\text { Colleagues }\end{array}$ & 0.61 & 0.86 & 0.61 \\
\hline Org. Image Disclosure & 0.74 & 0.80 & 0.74 \\
\hline Involvement & 0.51 & 0.93 & 0.51 \\
\hline $\begin{array}{l}\text { Recruitment and } \\
\text { Selection }\end{array}$ & 0.51 & 0.86 & 0.51 \\
\hline Remuneration \& Rewards & 0.58 & 0.87 & 0.58 \\
\hline Creative Suggestions & 0.71 & 0.92 & 0.71 \\
\hline $\begin{array}{l}\text { Training and } \\
\text { Development }\end{array}$ & 0.60 & 0.90 & 0.60 \\
\hline
\end{tabular}

Sumber: data primer, diolah, 2020

Verifikasi validitas diskriminan antara konstruk dapat dianalisis dengan estimasi matriks korelasi dan akar kuadrat dari varians rata-rata yang diekstraksi dari Konstruksi (AVE).

Tabel 3 menyajikan nilai-nilai yang dianggap memadai untuk validitas diskriminan, menurut Fornell dan Larcker (1981).

Untuk analisis model tersebut, kami melakukan uji dampak PSDM pada OCB. Hasil memungkinkan untuk menegaskan bahwa dimensi PSDM menjelaskan 31,7\% OCB, sejak $\mathrm{R}^{2}$ menjelaskan seberapa besar variabel dependen (OCB) dipengaruhi oleh variabel independen (PSDM). Faktor-faktor yang memiliki relevansi yang lebih besar dalam PSDM adalah mereka yang hadir lebih besar penjelasan $\left(\mathrm{R}^{2)}\right.$ dari varians dari PSDM. $\mathrm{R}^{2}$ adalah nilai yang disajikan di tengah lingkaran setiap variabel laten di PLS. Dalam urutan relevansi yang lebih besar, faktor-faktornya adalah: Keterlibatan $\left(\mathrm{R}^{2}=0,808\right)$, Pelatihan dan Pengembangan $\left(\mathrm{R}^{2}=0,761\right)$, Evaluasi Kinerja $\left(\mathrm{R}^{2}=0,734\right)$; Remunerasi dan Imbalan $\left(\mathrm{R}^{2}=0,680\right)$; Kondisi kerja $\left(\mathrm{R}^{2}=0,588\right)$ dan Rekrutmen dan Seleksi $\left(\mathrm{R}^{2}=0,420\right)$. 
Tabel 3 Hubungan antar Variabel dan Hasil dari $\beta, R^{2}$ dan Uji $t$

\begin{tabular}{|c|c|c|c|c|}
\hline & $\begin{array}{c}\text { Hubungan antar } \\
\text { Variabel }\end{array}$ & $\boldsymbol{\beta}$ & $\mathbf{R}^{2}$ & Uji $t$ \\
\hline $\begin{array}{l}\text { Pengaruh Variabel PSDM terhadap } \\
\text { variabel PKO }\end{array}$ & PSDM -> PKO & 0.563 & 0.317 & 9.859 **** \\
\hline \multirow{6}{*}{$\begin{array}{l}\text { Pengaruh Faktor-faktor PSDM pada } \\
\text { PKO }\end{array}$} & R\&S -> PKO & 0.012 & \multirow{6}{*}{0.421} & 1.059 \\
\hline & IN -> PKO & 0.285 & & 2.741 ** \\
\hline & T\&D -> PKO & 0.142 & & 1.182 \\
\hline & WC -> PKO & 0.096 & & 0.968 \\
\hline & PE -> PKO & 0.09 & & 0.102 \\
\hline & R\&R -> PKO & 0.148 & & 1.497 \\
\hline \multirow{3}{*}{$\begin{array}{l}\text { Pengaruh variabel PSDM terhadap } \\
\text { Faktor variabel PKO }\end{array}$} & PSDM $->C C$ & 0.185 & 0.034 & 1.805 \\
\hline & PSDM -> OID & 0.655 & 0.429 & 12.649 *** \\
\hline & PSDM $\rightarrow$ CS & 0.354 & 0.126 & $4.980 * * *$ \\
\hline
\end{tabular}

Untuk mengkonfirmasi signifikansi, digunakan tes bootstrap untuk mengukur uji $t$ antara beberapa sampel acak dari kasus. Uji $t$ ditemukan untuk hubungan (PSDM dan PKO) adalah $t=9.859 ; \mathrm{p}<0,001$, oleh karena itu signifikan. Berarti dapat dinyatakan bahwa PSDM yang didefinisikan oleh bagaimana organisasi mempengaruhi karyawan dalam situasi yang tidak ada peraturan, regulasi atau arahan yang menggambarkan perilaku yang diharapkan organisasi dari mereka.

Kemudian dilakukan uji pengaruh untuk mengidentifikasi $\beta$ dan R2 dari enam kebijakan yang membentuk PSDM pada PKO secara keseluruhan.

Saat diuji secara langsung, faktor PSDM secara simultan berdampak pada 42,1\% terhadap perilaku warganegara organisasi responden. Koefisien jalur $(\beta)$ menyoroti bahwa faktor yang memberikan hasil paling berpengaruh dalam perilaku kewarganegaraan organisasi adalah Keterlibatan $(\beta=0,285 ; \mathrm{p}<0,01)$, membenarkan hasil yang menunjukkan dampak kebijakan ini pada set PSDM. Hasil lainnya adalah sebagai berikut: Remunerasi $(\beta=0,148 ; p>0,05)$, Pelatihan dan Pengembangan $(\beta=0,142 ; p>0,05)$, Kondisi kerja $(\beta=0,096 ; p>0,05)$, Evaluasi kinerja $(\beta=0,090 ; p>0,05)$ dan Rekrutmen dan seleksi $(\beta=0,012 ; p>0,05)$.

Faktor keterlibatan memiliki hubungan yang signifikan dengan PKO $(\mathrm{t}=2,741$; $\mathrm{p}$ 
$<0,01)$. Praktik yang menunjukkan kepedulian organisasi terhadap kesejahteraan karyawan, serta mereka yang mengupayakan integrasi karyawan seperti pertemuan sosial, acara olahraga dan sosial, serta mempromosikan pengakuan atas pekerjaan tersebut. dilakukan, mereka mampu secara positif mengganggu kewarganegaraan organisasi karyawan.

Faktor imbalan menunjukkan $\mathrm{t}=1,497$ ketika kami menyelidiki hubungannya dengan PKO, oleh karena itu tidak signifikan. Hasil penelitian menunjukkan bahwa remunerasi yang sesuai dengan posisi yang dipegang atau tingkat sekolah, atau terkait dengan hasil yang diperoleh dalam prestasi kerja tidak berdampak signifikan terhadap kewarganegaraan organisasi. Selain itu, bagi responden, tawaran komisi, gratifikasi atau bonus memiliki pengaruh yang wajar terhadap sikap karyawan yang mengungkapkan organisasi.

Pengaruh pelatihan dan pengembangan terhadap PKO, diperoleh $\mathrm{t}=1,182$, yang tidak signifikan. Bagi pekerja yang berpartisipasi dalam studi ini, praktik dan kebijakan yang ditujukan untuk pengembangan keterampilan seperti partisipasi dalam kongres atau pelatihan, pemberian beasiswa penuh atau sebagian, dan merangsang pembelajaran dan produksi pengetahuan adalah faktor-faktor yang berdampak kecil pada perilaku mereka yang mewujudkan kewarganegaraan organisasi.

Di sisi lain, rekrutmen dan seleksi menunjukkan $\mathrm{t}=1,059$ dan oleh karena itu dianggap tidak signifikan. Oleh karena itu, kami dapat menegaskan bahwa penyebaran proses rekrutmen dan cara tes seleksi dilakukan dan diterapkan oleh organisasi tidak signifikan dalam hal menstimulasi perilaku kewarganegaraan organisasi di antara pekerja.

Hasil ini juga mengungkapkan bahwa Kondisi Kerja tidak berpengaruh pada PKO $(\mathrm{t}=$ 0,968). Berdasarkan hasil tersebut dapat dinyatakan bahwa rencana pencegahan kecelakaan, keselamatan kerja, fasilitas dan kondisi fisik (seperti suhu, pencahayaan, ventilasi dan kebisingan) dan kondisi ergonomis untuk melakukan pekerjaan bukanlah faktor yang berdampak signifikan terhadap kewarganegaraan organisasi pekerja.

Demikian pula, faktor Evaluasi Kinerja tidak berpengaruh pada perilaku kewargnegaraan organisasi juga. Tes menunjukkan $\mathrm{t}=0,102$, terbukti tidak signifikan. Bagi responden, proses evaluasi kinerja dalam semua konteksnya (subsidi untuk promosi, 
kriteria yang ditetapkan oleh organisasi, bentuk pencapaian dan diseminasi hasil kepada karyawan) tidak berpengaruh pada perwujudan perilaku warganegara organisasi. Selain itu, dilakukan juga uji pengaruh PSDM pada faktor-faktor penyusun PKO, yang bertujuan untuk mengidentifikasi $\beta$ dan R2. Kami dapat mengidentifikasi, melalui jalur dan koefisien determinasi, bahwa kebijakan dan praktik sumber daya manusia berdampak pada kerja sama rekan kerja di 3,4\%. Di antara faktor-faktor yang membentuk PKO, kerjasama dengan rekan kerja menunjukkan pengaruh PSDM yang paling rendah. Antara variabel PSDM dan OID (pengungkapan citra organisasi) kami menemukan $\beta=0,655$ dan $\mathrm{R} 2=0,429$ dan antara PSDM dan CS (saran kreatif) nilai $\beta=$ 0,354 dan $\mathrm{R} 2=0,126$, nilai jauh di atas dimensi CC (kerja sama dengan rekan kerja) : $\beta$ $=0,185$ dan $\mathrm{R} 2=0,034$. Ini berarti bahwa perilaku yang bertujuan untuk menyebarkan citra organisasi dan saran kreatif dalam lingkungan kerja, untuk sampel ini, adalah yang paling dipengaruhi oleh kebijakan dan praktik sumber daya manusia yang ditetapkan oleh organisasi.

Dengan uji t, dengan menggunakan metode Bootstrap, dapat diidentifikasi tingkat signifikansi hasil. Hasil penelitian menunjukkan bahwa dampaknya signifikan dalam hal dimensi OID dan CS. Dapat diamati bahwa pengaruh terbesar yang disebabkan oleh variabel PSDM pada faktor PKO berada pada OID (pengungkapan citra organisasi) dengan $\mathrm{t}=12,649 ; \mathrm{p}<0,001$. Hasil penelitian mengungkapkan bahwa kebijakan dan praktik SDM secara signifikan memengaruhi perilaku pekerja ketika mereka perlu membela organisasi tempat mereka bekerja dalam menghadapi kritik eksternal.

Pengaruh yang disebabkan oleh PSDM pada CS (saran kreatif) juga signifikan, meskipun pada tingkat yang lebih rendah). Hasil uji Bootstrap menunjukkan $t=4,980$; p <0,001. Bagi peserta, penyajian saran atau ide kreatif yang membawa solusi atas permasalahan yang ditemukan pada tugas atau bidang kerja sangat dipengaruhi oleh kebijakan dan praktik sumber daya manusia yang ditetapkan oleh organisasi tempat mereka bekerja. Sedangkan dimensi kerjasama dengan rekan kerja memberikan hasil yang paling rendah $(\mathrm{t}=1.805)$, sehingga tidak signifikan jika dianalisis dampak yang dialami oleh PSDM. Menawarkan dukungan kepada kolega dalam menghadapi masalah pribadi, serta membantu mereka yang kurang berpengalaman, yang mengalami kesulitan atau yang bingung di tempat kerja, tidak berdampak signifikan pada PSDM 
organisasi.

Tabel 3 menunjukkan hasil menurut pengaruh variabel PSDM terhadap variabel PKO (beserta komponennya), selain pengaruh faktor komponen variabel PSDM terhadap variabel PKO.

Berdasarkan hasil yang telah diverifikasi, dapat dilihat bahwa dalam menganalisis pengaruh variabel PSDM terhadap variabel PKO, baik koefisien determinasi maupun uji $\mathrm{t}$ menunjukkan signifikan $(\mathrm{R} 2=0,317$ dan $\mathrm{t}=9,859)$. Ketika meneliti pengaruh yang dimiliki enam kebijakan sumber daya manusia terhadap perilaku kewarganegaraan organisasi, tercatat bahwa ada hubungan yang koheren antara hasil koefisien jalur dan uji t, mengungkapkan bahwa hanya Keterlibatan yang secara signifikan berdampak pada perilaku kewarganegaraan organisasi $(\beta=0,285$ dan $t=2,741)$. Akhirnya, hasil tes yang dilakukan menunjukkan bahwa koefisien determinasi dan uji $t$ Student menunjukkan pengungkapan citra organisasi sebagai PKO faktor yang menerima dampak terbesar dari kebijakan dan praktik sumber daya manusia $(\mathrm{R} 2=0,429$ dan $\mathrm{t}=$ 12,649), diikuti oleh faktor saran kreatif $(\mathrm{R} 2=0,126$ dan $\mathrm{t}=4,980)$.

\section{KESIMPULAN}

Studi tentang perilaku kewarganegaraan organisasi telah mendapatkan perhatian yang cukup besar dalam beberapa tahun terakhir di seluruh dunia. Manajer telah menunjukkan minat pada fakta bahwa sumber daya manusia terletak pada perbedaan kompetitif yang mereka cari untuk organisasi tempat mereka bekerja. Dan perilaku sumber daya ini sangat mendasar agar daya saing dan efektivitas organisasi dapat dicapai.

Melakukan sesuatu yang lebih, mencapai apa yang tidak terduga, terbukti sebagai kolaborator altruistik dan melebihi kewajiban, adalah sikap yang telah dituntut oleh organisasi di antara para pekerjanya. Inilah yang disebut perilaku kewarganegaraan organisasional.

\section{DAFTAR PUSTAKA}

Armstrong, M, 2009, Armstrong'S Handbook Of Human Resource Management Practice. $11^{\mathrm{a}}$.Ed. London: Kogan Page.

Basuki, 2021, Pengantar Metode Penelitian Kuantitatif, Penerbit Media Sains 
Indonesia, Bandung, https://scholar.google.co.id/citations?user=ka0E86IAAAAJ Dessler, Garry, 2010, Manajemen Sumber Daya Manusia, Jilid 1, Prehallindo, Jakarta.

Hair, JR., JF; Anderson, RE; Tatham, RL; Black, WC., 2005, Analyzis Multivariate. 5. Ed. Porto Alegre: Bookman.

Hair, JR., JF; Hult, GTM; Ringle, CM; Sarstedt, M., 2013, A Primer On Partial Least Squares Structural Equation Modeling (PLS-SEM). Thousand Oaks: SAGE Publications, 2013.

Janssen, O.; Huang, X.,2008, Us And Me: Team Identification And Individual Differentiation As Complementary Drivers Of Team Members' Citizenship And Creative Behaviors. Journalof Management, V. 34, N. 1, Hal. 69-88.

Katz, D.; Kahn, RL., 1978, The Social Psychology Of Organizations. 2a .Ed. New York: John Wiley And Sons.

Kehoe, RR; Wright, PM, 2013, The Impact Of High-Performance Human Resource Practices On Employees' Attitudes And Behaviors. Journal Of Management, V. 39, N. 2, P. 366-391, 2013.

Khan, AS; Rasheed, F., 2015 Human Resource Management Practices And Project Success, A Moderating Role Of Islamic Work Ethics In Pakistani Project-Based Organizations. International Journal Of Project Management, V. 33, N. 2, P. 435445.

Lam, W.; Chen, Z.; Takeuchi, N.,2009, Perceived Human Resource Management Practices And Intention To Leave Of Employees: The Mediating Role Of Organizational Citizenship Behavior In A Sino-Japanese Joint Venture. The International Journal Of Human Resource Management, V.20, N.11, P.22502270.

Legge, K.2006, Human Resource Management. In: ACKROYD, S.; BATT, R.; THOMPSON, P.; TOLBERT, PS (Eds).The Oxford Handbook Of Work And Organization. New York: Oxford University Press, 2006, Pp.220-241.

Lepak, Dp; Liao, H.; Chung, Y.; Harden, EE., 2006, A Conceptual Review Of Human Resource Management Systems In Strategic Human Resource Management Research. Research In Personnel And Human Resource Management, V. 25, N. 06, P. 217-271, 2006.

Luthans, F., 2002, Positive Organizational Behavior: Developing And Managing Psychological Strenghts.Nova York: Academyof Management Executive, 2002.

Organ, DW; Podsakoff, MM; Mackenzie, SB., 2006, Organizational Citizenship Behavior. Its Nature, Antecedents And Consequences. London: Sage Publication.

Pavalache-Ilie, M., 2014, Organizational Citizenship Behaviour, Work Satisfaction And Employee's Personality. Procedia - Social And Behavioral Sciences, V. 127, N. 1983, P. 489-493.

Podsakoff, PM; Mackenzie, SB; Paine, JB; Bachrach, DG, 2000, Organizational Citizenship Behaviors: A Critical Review Of The Theoretical And Empirical Literature And Suggestions For Future Research. Journalof Management, V.26, N.3, 513-563.

Snape, E.; Redman, T., 2010, HRM Practices, Organizational Citizenship Behavior, And Performance: A Multi Level Analysis.Journalof Management Studies, V.47, 
N.7, P.1219-1247, November.

Taghinezhad, F., 2015,. Antecedents Of Organizational Citizenship Behavior Among Iranian Nurses: A Multicenter Study. BMC, V. 8, N. 547, P. 1-9, 2015.

Tang, TW; Tang, YY, 2012, Promoting Service-Oriented Organizational Citizenship Behaviors In Hotels: The Role Of High-Performance Human Resource Practices And Organizational Social Climates. International Journal Of Hospitality Management, V.31, P. 885-895.

Widyanti Rahmi, Deli Anhar dan Basuki, 2020, Pengaruh Pengembangan Karir Terhadap Komitmen Organisasional, Al Ulum, Ilmu Sosial dan Humaniora, Vol.6, No.2, 79-90.

Widyanti, Rahmi, 2019, Perilaku Organisasi: Teori dan Konsep, Jilid 1, Penerbit Media Sains Indonesia Bandung, https://scholar.google.co.id/citations?user=ka0E86IAAAAJ 